\title{
Correlation Study: CEM Scores and Customer Perception Value in Chick-fil-A Teterboro from 2018-2019
}

\author{
Amanda Feliciano ${ }^{1}$ and Norina Sfeir ${ }^{1}$ \\ ${ }^{1}$ Bergen County Technical High School, Teterboro, NJ, USA
}

\begin{abstract}
The monitoring of customer service experiences for fast food restaurants has been on the rise for past three decades because of technological advances. Having access to the current features helps businesses determine what factors to consider for improving their company. There has been research done on research chains such as Chipotle, Subway, KFC, Dairy Queen, and Taco Bell. Each restaurant focuses on similar factors, but there has been little to no research done on the fast-food restaurant, Chick-fil-A regarding CEM scores and customer perception. Chick-fil-A is an extremely well-known fast-food place known to have outstanding customer service because of their overall politeness and fast service. This study aims at looking into one specific Chick-fil-A location in Teterboro, New Jersey, which is known to be in the top $20 \%$ of Chick-fil-As in the United States. This research study used stratified sampling in order to conduct a Spearman Correlation Analysis that answered the research question, "Is there a correlation between 4 main components of customer service and an effect on the customer service environment in Chick-fil-A Teterboro, from the years 2018-2019?" Results concluded there were only two direct correlations between two components. The two factors that had the highest correlation with one another were Overall Customer Satisfaction levels and the Attentive/ Courteous component in connection to the overall value of the customer service environment.
\end{abstract}

\section{Introduction}

\section{Restaurant Research Employing an Analysis}

In the food service industry, different components of customer service are measured and analyzed to gauge the overall quality of a restaurant (Haumann et al 2014). However, there is still little research in fast food restaurants regarding which of these components are the most effective in understanding the customer service quality, which is defined as customer perception in this study. Customer perception helps businesses analyze and understand what attributes need improvement in order to satisfy the customer to their fullest potential.

Chick-fil-A is a franchise well known for exceptional customer service, in regards to its well-known saying, "My pleasure," constant eye contact, and showing an overall pleasant demeanor, indicated by QSR (Quick Restaurant Service) Magazine (QSR Magazine, 2018). QSR Magazine is known to be the leading source of the 50 biggest restaurant brands in America regarding the $\$ 300$ billion limited-service restaurant industry. The QSR Magazine defined the limited-service restaurant industry as a full-service takeaway, fast-casual dining, traditional fast food, concessions, convenient stores, and additional parts of the foodservice industry. In 2016, QSR Magazine conducted a study that included a survey where 10,000 US consumers evaluated their recent experiences with different fast-food companies. Chick-fil-A was ranked \#1 when taking into consideration 3 factors: success, effort, and emotion. The final score was an average of those 3 metrics (QSR Magazine, 2018). The QSR Drive Thru Performance team used 2 years' worth of data when determining how different menu categories and certain day parts shaped the experience from the DriveThru. They broke down the data by each chain, where they researched 11 quick serves, along with 4 fast casuals, 
which hadn't been implemented before. This resulted in the team expressing where each restaurant would land when analyzing the critical metrics of drive thru. In their study, Chick-fil-A demonstrated, once again, their strong customer service attributes (QSR Magazine, 2018). Customers go to restaurants with top ratings, which include factors such as overall satisfaction, fast service, attentive and courteous, store cleanliness, and the overall value of their experience (Ryu, Han 2010). Those studies used quantitative methods to come to that general conclusion. According to QSR Magazine's study, Chick-fil-A is a leading indicator of how a fast food restaurant should be from the customer service aspect. It is important to understand the factors behind their success. There was a weekly analysis conducted for 5 key components from customer feedback, but this study focused on 4 of them because of their numerical relevance, using a quantitative study. This weekly analysis is called the 'Customer Experience Monitor' (CEM) that has the purpose of monitoring customers' perspectives and finding a way to focus on the customer experience from their perception, along with managing the growing complexity this system creates (CIO From IDG, 2020). CIO (Chief Information Officer) Magazine is known to be involved with IT and current technology, where many of the strongest enterprise CIOs and business technology executives. These readers obtain major insights on development regarding their career and employees, hiring practices, certification, and making sure they have an elite foundation in digital transformation regarding their business. This system continues to be the future of monitoring customer service attributes and many arguments continue to argue why it needs to be implemented for future purposes, especially for enterprise IT and business leaders (CIO From IDG, 2020). In their article titled, "Why the customer experience is the future of monitoring", they made clear technology continues to become difficult and the importance of monitoring solutions continue to rise, especially for customer service. (CIO From IDG, 2020). Although different companies approach this situation differently, many business leaders continue to predict that the future lies in a monitoring approach that goes beyond the current stack. Previous research findings show the analysis of different attributes is important for making decisions for future restaurant implementations (CIO From IDG, 2020).

A number of hypotheses concerning the nature of restaurant customer perception has been advanced by various authors. A significantly high proportion of the studies in the field recommended the use of a conjoint analysis. This is a highly recommended analytic method when looking into the importance of restaurant factors. (Rhee, et al 2016; Koo, et al 1999; Schaupp 2005; Tarka 2008; Cattin et al 1982). It is a useful tool when one wants to address and understand the effects of various factors of production when dealing with production selection by customers.

For this research, a conjoint analysis was considered, but not implemented because of the data misspecifications the program had. The program did not work effectively, and after trying other software, the researcher had complications with the data entered and didn't give the researcher the results they needed to complete this paper. The next analytic method for recording the importance of restaurant factors was a Spearman Correlation Analysis, and this took the data the researcher received from their sources, instead of completely rejecting it like the conjoint analysis did. This analytic tool was the second-best alternative to researching business attributes and customer perception, discussed in the "Value" and "Current Knowledge and Gaps" section of the Literature Review because of its significance and similarity to the Conjoint Analysis.

\section{Literature Review}

It is known that customers tend to select a restaurant because they consider the different attributes holistically, rather than individually (Rhee et al 2016). Fast food online customers would be that they would be more entitled to analyze price, atmosphere, food and value after their experience, then end up prioritizing attributes which mean the most to them (Rhee et al 2016). When customers are more likely to contribute their own opinions on the different attributes, this would encourage the managers to implement effective change in the strategies currently being used because of different ways customers' perceive in a product or attributes of service. When dealing with the restaurant, the following studies influenced the choice of analysis, although not all examine the same exact attributes or the same study technique, but surveys and similar topics. 
In Rhee et al.'s 2016 study, the authors explored the subject of when people who are dining out when traveling and the study used a multiple-case study analysis, which selected three New York City restaurants. This is similar to the study based in Hong Kong. A study by Koo et al. (1999), elaborated further and revealed that conjoint analyses have appeared as modern techniques for the research community where it revealed consumers' standpoints for restaurants. The technique is generalized to restaurant choices in Hong Kong, and other countries (Rhoo et al 1999). In another study, Ryu et al (2009), the researchers looked into relationships with three main factors of quality that included service, environment and food of the physical place, a moderator which was the price, and satisfaction, as well as behavioral intentions. The study called attention to the little research done about behavior intentions were affected by different qualities of customer satisfaction (Ryu et al 2010). A study by Cheng et al. (2011) advances the notion of looking into the relation with customer loyalty and satisfaction in regards to the fast food industry (Cheng et al 2011). These studies indicate the combined variables related to what characteristics make up the fast-food industry. These several studies had examinations of the relations with customer loyalty, customer satisfaction, and service quality, is evidence regarding the affect the way a business run. It is important to make sure the attributes have good relationships with the customer environment because this would lead to the success of a business.

According to most of the literature produced on the subject, they not only compare to one another because of the method, but also because of the different attributes. They described how essential different ratings are in regard to the failure and success of e-commerce businesses and the fast food industry (Batt et al 1999). There is a growing body of evidence that concluded the 4 main attributes: atmosphere, value, accommodation and food, are considered the most consequential factors when one selects a restaurant to go to, where other studies used surveys and questionnaires to contribute to the claim (Rhee et al 2016). However, the studies which use "online review scores" have the potential of being more natural and convincing compared to those that employ a questionnaire research method that shows the true post-behavior factors (Rhee et al 2015). Subsequent inquires have filled the gap when examining important customer service attributes and if they correlate to the customer service environment, along with analyzing the most crucial factor which contributes to the increase or decrease in sales.

\section{Food}

Haumann et al (2014) gave credence to the two most important concepts in relationship marketing, known as customer-company identification and customer satisfaction. There is scarce information known about the effectiveness of different theoretical roots as well as reflecting on their effectiveness in the future. An indication of the importance attached to the study of Haumann is to fill the gaps and provide a comparative analysis regarding satisfaction of customers in relation to customer-company identification to improve and see customer expectations for the future. (Haumann et al 2014). When considering the two most important concepts, this helps analyze certain attributes tangential to customer perception. This theoretically improve business success of sales because they are aware of the problems that need development and satisfies the customer. This continually analyzes the correlation between attributes of business and customers' value of perception to encourage growth in the company.

\section{Service}

This pop article from QSR Magazine focuses on how Chick-fil-A continues to impress with its customer services. It depicts the different components which make up its groundbreaking customer service, along with including data from a survey of 10,000 U.S. consumers which asked the participants to evaluate their recent experiences with a company, dealing with three factors: success, effort and emotion. The percentages resulting from this survey are listed for the different fast-food brands, such as: Chick-fil-A, Chipotle, Subway, KFC, Dairy Queen, and Taco Bell. The goal of this source is to be able to optically discern the factors which come into play when answering the question of why Chick-fil-A is top with their customer service scale. Pertinent to food, both go hand and hand with one another to improve customer service perception in regards to these general characteristics. If the food and service are good in a 
business, this will improve customer-company identification and customer satisfaction because one is evaluating certain experiences from surveys to understand any limitations the business needs to advance for the future.

\section{Environment}

The main purpose of the study, "Strengthening Customer Loyalty through Intimacy and Passion: Roles of CustomerFirm Affection and Customer-Staff Relationships in Services," was to increase the understanding of current satisfaction loyalty, to see how customers' affection connects with a firms' passion and intimacy. The study analyzed how to build onto the customer loyalty in services (Yim et al 2008). The authors of this source use a bi-level model, which is having functions on two levels, where they take into consideration customer-staff and customer-firm interactions (Yim et al 2008). This is used from another survey and study research in context of two services. This pointed out 4 main results, along with providing several implications for not only researchers, but also managers. It demonstrated how passion and intimacy affect customer service interactions. Alongside, this demonstrates how a company can manage customer-staff relationships in the right manner, properly. This shows how having a healthy environment promotes positivity in stores, as well as the cleanliness for people to continue to come back.

The beginning of the article, Vogel et al (2008) mentions the flaws when determining the relation with future sales and customer attitudes. The authors elaborated further and determined how customer attitudes and their behaviors are affected by customer perceptions and marketing advertising (Richelsen et al 2008). These would be resolved by the sales of the future by utilizing an implement which predicts the customer equity drivers and how this can show future sales. The study was used to see customer service drivers and future sales, when utilizing certain attributes in order to determine which factors are vital for future implementations.

The ideas expressed by the environment, food and service support the premise that certain attributes have an effect on customer perception, and it is vital to look into customers' commentary from one of the most used resources, surveys. The researcher implemented those general categories into this study in order to see the effect of 4 main attributes and if they correlate to the value of customer perception in Teterboro, Chick-fil-A from the years 20182019.

Value

Although there are studies which conducted similar analyses regarding customers' emotions and effects of certain attributes, there is little to no academic research done regarding the effectiveness these qualities have on the customer service environment of a specific fast-food restaurant. Previous research has explored similar issues, but managers and academics are unaware of how the merged results of quality elicit the state of happiness from a customer for particular restaurants, using the Spearman Rho Correlation Analysis. Most researchers used the Conjoint Analysis, but there hasn't been much research conducted using the Spearman Rho Correlation Analysis, shown by prior studies its effectiveness on certain attributes and customer satisfaction.

Because there has been little to no research done on the comparison with the effectiveness of customer service and customer satisfaction, this research paper had the purpose of conducting a Spearman Rho Correlation Analysis, determining the effectiveness between 4 core customer service components (overall satisfaction, fast service, attentive courteous, and store cleanliness) on customer perception of Chick-fil-A because of prior indicators that customers' inputs are vital to the success of a business, and knowing the areas that need growth.

\section{Current Knowledge and Gaps}

Being able to identify different attributes that correspond to the success and failure of a restaurant is extremely important, not only for this Chick-fil-A franchise, but for additional fast-food companies, and retail stores. Throughout 
previous years, studies have identified factors which contributed to the change in customer satisfaction, rankings, and service quality dimensions.

The most common method used was a Conjoint Analysis, a de-compositional statistical method to examine the attributes based on the overall ratings or rankings of each combination of attributes (Richelsen et al 2008). But, there are few sources that implemented a Spearman Correlation Analysis, which measures the strength between two variables and the direction of the relationship (QuestionPro, 2020). For instance, the study "Service Quality and its Relationship with Customer Satisfaction and Loyalty in a Saudi Arabian Automobile Company" used this method as a way of measuring customer service. The analysis concluded that all quality dimensions had a positive effect in replication to customer loyalty and customer contentment. After getting the results, the study overall concluded that it is important to make periodic quality assessments. Some long-standing assumptions reveal how important it is to receive customer input and see if there is a way to improve these quality attributes from the customers' valuable perception, has prior studies investigated.

Severe assumptions can be deduced from the current research literature. These studies resulted in identifying and fine-tuning any gaps that come about between visually perceiving authentic perceived service quality, as well as customers' prospects of service. Prior studies helped the researcher determine the best methodology to go about customer perception and how often the restaurant should make assessments to improve their CEM scores. There has been little investigation on this topic of the correlation between the 4 main attributes and customer perception. Literature reveals a diversity of ideas on this issue, and it is predominant to look into these factors for Chick-fil-A and additional fast-food restaurants who aim on improving their customers' pleasure from their experience. The notion of the 4 attributes potential correlation to customer perception is supported by the research mention above, and how they need extra steps to help improve levels of customer perception to make the company reliable and enjoyable. If businesses do not take the extra precautions, theoretical and evidential speculations conclude they will not succeed without taking into account main attributes and if there is a correlation with customer perception.

\section{Methods}

\section{Correlation Analysis (Spearman Rho)}

The Spearman Correlation Analysis is one tool that hasn't been used that often in fast food marketing research regarding main qualities and their effect on the customer service environment. This is an analysis that measures the strength of association between two variables, and the relationship direction (QuestionPro, 2020). For the strength of the relationship, the values are between both positive and negative one. The relation with the components analyzed will become weaker as they get closer to 0 . The coefficient sign indicates the relationship direction. A negative sign demonstrates an inverse, while a positive sign demonstrates a direct relationship (QuestionPro, 2020).

For the sole purpose of this research on the fast-food restaurant Chick-fil-A, this correlation analysis accounted for the 4 different components (overall satisfaction, fast service, attentive courteous, and store cleanliness) being the independent variables. These independent variables demonstrated the top 4 qualities for a company to look into when improving overall customer satisfaction. The dependent variable was the customer service environment, defined as the overall 'value' from customer response surveys. The purpose was to determine if there were any correlation between the overall value (perception) from customers, and any of the 4 components mentioned in the previous sentence. This demonstrated factor(s) that contributed the most to the overall value in the customer environment. Because there are different variations of a correlation analysis, Minwir Al-Shammari and Ahmad Samer Kanina published an article in the Global Journal of Management and Business Research that fixated on the cognation with customer loyalty, accommodation quality, and customer gratification in the Saudi Arabian Automobile Company (SAACO). Described further in the Methods portion of this paper, for the strength of the relationship, the values are between both positive and negative associations. As a result of utilizing the Spearman Correlation Analysis, this made 
clear how customers' perceptions were positively affected by the 4 components in this paper. In order to amend market shares, profitability, contentment from customers and their loyalty, there needs to be more improvements in the quality of accommodation (Shammari et al 2015).

\section{Survey (Approval)}

The researcher did not create the survey discussed in the Appendix but received approval from the operator at this Chick-fil-A location to use the data for each survey sent in by customers because they were an employee. This used specific login instructions and permission from the website in order to have access to the survey data.

\section{Simple Random Sampling}

The data collection for this research paper was based on the time period of January 1, 2018 to December 31, 2019, using the Simple Random Sampling (SRS) Probability Method. This is defined as a technique where a large group (a population) is used, and subjects (the sample) are chosen from that group. This is similar to the system of the lottery, because each person has a fair chance of being picked for the sample (stat.yale.edu). There was a total of 720 total responses taken from the population of 3893 respondents from the 2 year period, which accounted for approximately $18.5 \%$ of the total population.

\section{Logistics, Aim and Value of Research}

This research examined the CEM (Customer Experience Monitor) scores from the surveys, and how they affected the overall customer service environment. This research paper inspected the 4 core components of Chick-fil-A customer accommodation and their correlation to the customer service environment of one Chick-fil-A location.This involved observing the CEM scores in this restaurant. Indicated in the previous section, these scores from the scores were put together by results from the survey. The time period ranked from January 1st 2018, to December 2019.

These study results will help current and future managers and academics understand how important different components of customer service are, when implementing new methods for the store. This would improve the overall value of the customer service environment. It is important to demonstrate ways that restaurants are able to increase customer loyalty by improving their understanding of the roles price perception, physical environmental, and customer satisfaction (Han et al 2009).

This survey pertains to the current research study because its replications will help the researcher answer to the question regarding the correlation between the 4 main components of customer accommodation and the value gained from filling out the survey. The overall value is then calculated by the Chick-fil-A system based on the customer survey responses, using numbers. One section that was excluded was "Order Accuracy" because it did not provide numerical calculations, and had customers answer, 'Yes' and 'No'. Therefore, there were only 4 out of the 5 major components of customer service accounted for in this research paper.

\section{Results}

\section{Data Collected}

To reiterate, the paper addressed the question, 'Is there a correlation between 4 main components of customer service and an effect on the customer service environment in Chick-fil-A Teterboro, from the years 2018-2019?' This research paper enforced the Spearman Rho Correlation Analysis, mentioned in the previous section. In order to receive the 
results, QuestionPro's analytic tools were used and paid for. The membership was used for a 2 month period with the purpose of having access to multiple features. QuestionPro is known to provide powerful online survey software.

The numerical values below were calculated using the customer survey results by each of the 4 attributes, along with the overall value from the perception of their experience. They are in respective order as follows: Overall Satisfaction, Fast Service, Attentive/ Courteous, Cleanliness in respect to customer perception.

These pie charts included the number of times the scores of 1-5 were recorded, and those results were then converted to percentages. These are only accounting for how many times a score was chosen for each attribute in a pictorial representation.

Following the pie charts is a record of the number of times the 720 respondents rated that category, from 15. A ranking of 5 entailed highly satisfied, 4 is not highly satisfied, 3,2 and 1 are scored for less than satisfied. These respondent totals created the percentages indicated in the pie charts.

Anything between the values of 0.80 to 0.65 , known to be the set threshold and was colored light green with a low strength of relationship. Anything between 0.80 and 0.90 , is colored medium green, with a slightly stronger relationship. Dark green would designate a high level of correlation between the two variables, if higher than the value 0.90. An inverse correlation was not used because the overall distribution of the data points had a direction correlation between 0.60 to 1 . Negative would have had to be below 0 which would demonstrate no correlations at all.

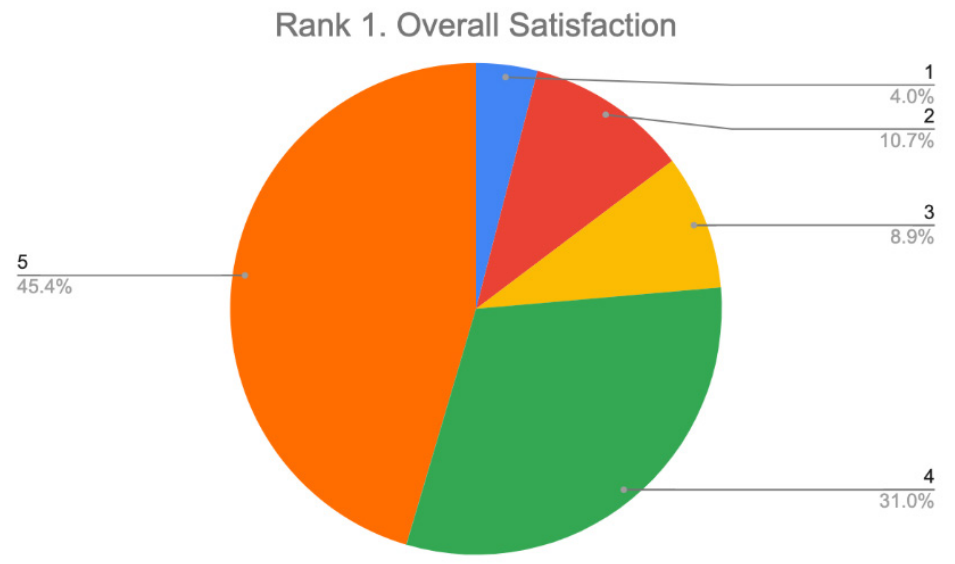

Figure 1. This is a pie chart of the first component analyzed: Over Satisfaction. 1: $4 \%$ of people ranked it 1, 10.7\% of people ranked it $2,8.9 \%$ of people ranked it $3,31 \%$ of people ranked it 4 , and $45.4 \%$ of people ranked it 5 . Overall, most people were finally satisfied with the component of Overall Satisfaction.

Table 1. This demonstrates how many people voted on the scale of 1-5 for each component, which represented the pie chart above. 29 ranked 1, 77 people ranked 2, 64 people ranked 3, 223 ranked 4, and 327 people ranked 5.

\begin{tabular}{|c|c|c|c|c|}
\hline 1 & 2 & 3 & 4 & 5 \\
\hline 29 & 77 & 64 & 223 & 327 \\
\hline
\end{tabular}




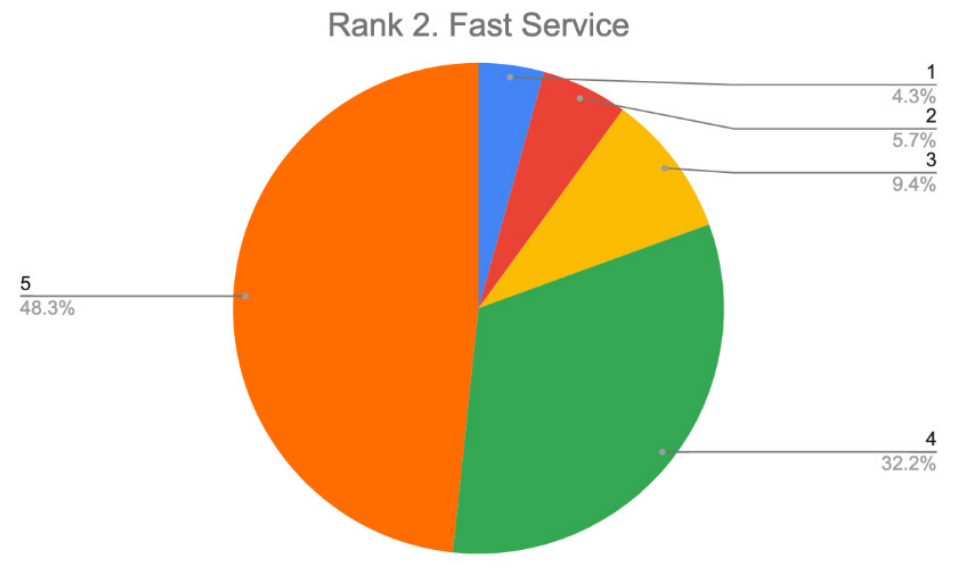

Figure 2. This is a pie chart of the first component analyzed: Fast Service. $4.3 \%$ of people ranked it 1, 5.7\% of people ranked it $2,9.4 \%$ of people ranked it $3,32.2 \%$ of people ranked it 4 , and $48.3 \%$ of people ranked it 5 . Overall, most people were highly satisfied with the component of Fast Service.

Table 2. This demonstrates how many people voted on the scale of 1-5 for each component, which represented the pie chart above. 31 ranked 1, 41 people ranked 2, 68 people ranked 3, 232 ranked 4, and 348 people ranked 5 .

\begin{tabular}{|c|c|c|c|c|}
\hline 1 & 2 & 3 & 4 & 5 \\
\hline 31 & 41 & 68 & 232 & 348 \\
\hline
\end{tabular}

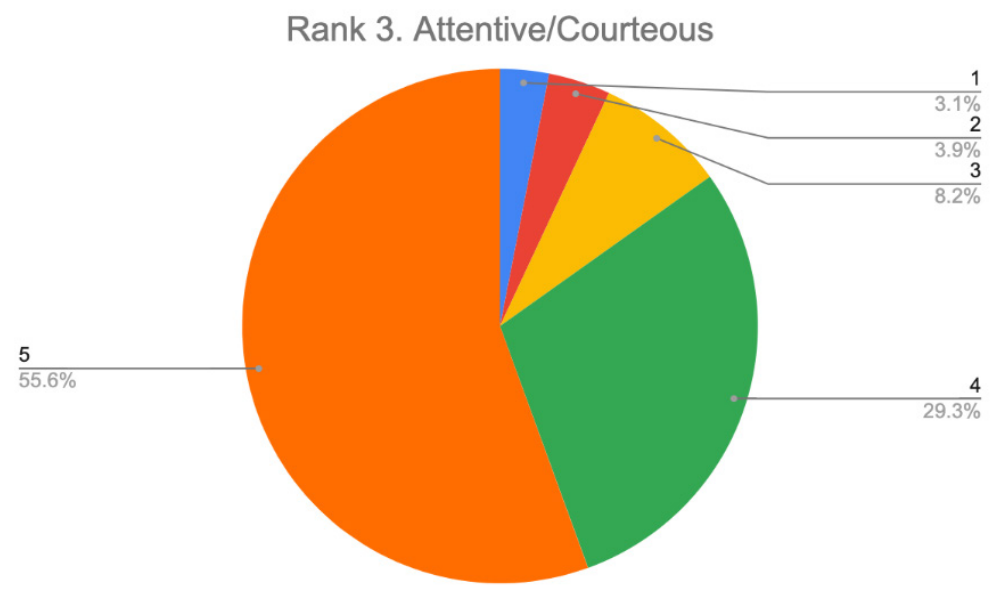

Figure 3. This is a pie chart of the first component analyzed: Attentive Courteous. 3.1\% of people ranked it 1, 3.9\% of people ranked it $2,8.2 \%$ of people ranked it 3,29.3\% of people ranked it 4 , and $55.6 \%$ of people ranked it 5 . Overall, most people were highly satisfied with the component of Attentive/ Courteous. 
Table 3. This demonstrates how many people voted on the scale of 1-5 for each component, which represented the pie chart above. 22 ranked 1, 28 people ranked 2, 59 people ranked 3, 211 ranked 4, and 400 people ranked 5.

\begin{tabular}{|c|c|c|c|c|}
\hline 1 & 2 & 3 & 4 & 5 \\
\hline 22 & 28 & 59 & 211 & 400 \\
\hline
\end{tabular}

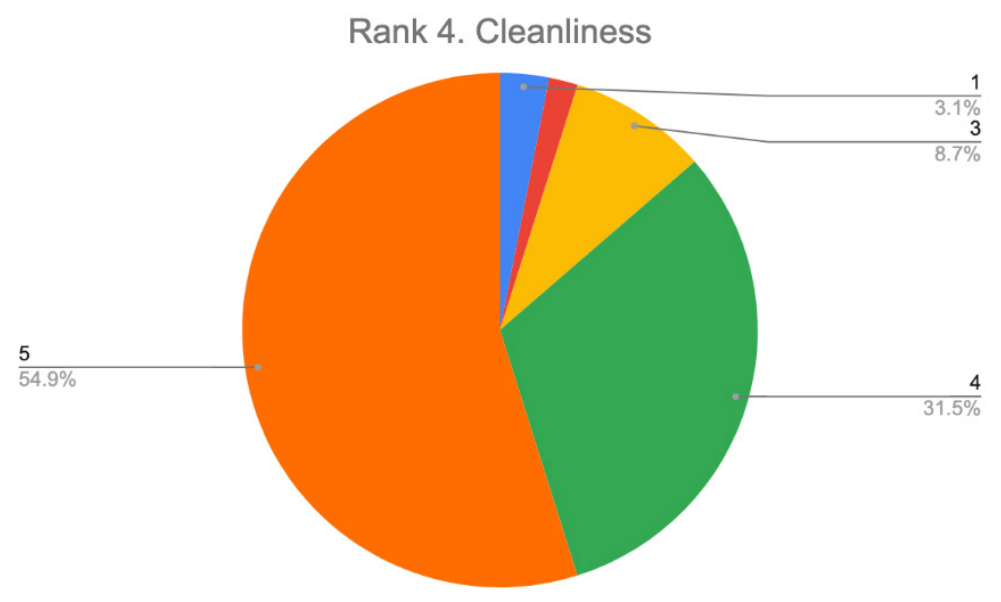

Figure 4. This is a pie chart of the first component analyzed: Cleanliness. $3.1 \%$ of people ranked it $1,1.8 \%$ of people ranked it $2,8.7 \%$ of people ranked it $3,31.5 \%$ of people ranked it 4 , and $54.9 \%$ of people ranked it 5 . Overall, most people were highly satisfied with the component of Cleanliness.

Table 4. This demonstrates how many people voted on the scale of 1-5 for each component, which represented the pie chart above. 22 ranked 1, 13 people ranked 2, 63 people ranked 3, 227 ranked 4, and 395 people ranked 5.

\begin{tabular}{|c|c|c|c|c|}
\hline 1 & 2 & 3 & 4 & 5 \\
\hline 22 & 13 & 63 & 227 & 395 \\
\hline
\end{tabular}

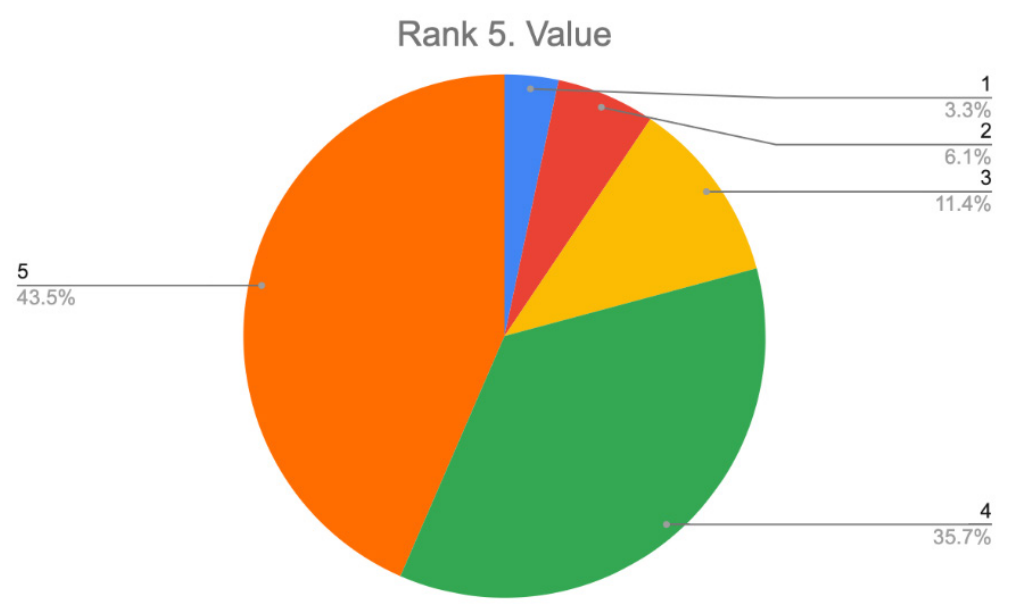


Figure 5. This is a pie chart of the first component analyzed: Value. 3.3\% of people ranked it 1, 6.1\% of people ranked it $2,11.4 \%$ of people ranked it $3,35.7 \%$ of people ranked it 4 , and $43.5 \%$ of people ranked it 5 . Overall, most people were highly satisfied with their overall customer service experience.

Table 5. This demonstrates how many people voted on the scale of 1-5 for each component, which represented the pie chart above. 24 ranked 1, 44 people ranked 2, 82 people ranked 3, 257 ranked 4, and 313 people ranked 5.

\begin{tabular}{|c|c|c|c|c|}
\hline 1 & 2 & 3 & 4 & 5 \\
\hline 24 & 44 & 82 & 257 & 313 \\
\hline
\end{tabular}

\section{Statistical Results and Analysis}

The pie charts and tables did not have any connection to the chart above. They were used solely for the purpose of how many people ranked the different attributes, along with the overall value of their perception.

The attributes and the overall value are labeled both horizontally and vertically. This had the purpose of seeing if there are any relationships shown between any of the components, in relation to the effect on the customer environment, labeled as 'Value'.

Table 6. Numbers are derived from Question Pro's analytic tools

\begin{tabular}{|c|c|c|c|c|c|}
\hline & $\begin{array}{c}\text { [Q1] Overall } \\
\text { Satisfaction }\end{array}$ & $\begin{array}{c}\text { [Q2] Fast Ser- } \\
\text { vice }\end{array}$ & $\begin{array}{c}\text { [Q3] Attentive/ } \\
\text { Courteous }\end{array}$ & $\begin{array}{c}\text { [Q4] Cleanli- } \\
\text { ness }\end{array}$ & [Q5] Value \\
\hline $\begin{array}{c}\text { [Q1] Overall } \\
\text { Satisfaction }\end{array}$ & 1 & 0.56 & 0.62 & 0.47 & 0.76 \\
\hline $\begin{array}{c}\text { [Q2] Fast Ser- } \\
\text { vice }\end{array}$ & 0.56 & 1 & 0.62 & 0.51 & 0.57 \\
\hline $\begin{array}{c}\text { [Q3] Attentive/ } \\
\text { Courteous }\end{array}$ & 0.62 & 0.62 & 1 & 0.58 & 0.63 \\
\hline $\begin{array}{c}\text { [Q4] Cleanli- } \\
\text { ness }\end{array}$ & 0.47 & 0.51 & 0.58 & 1 & 0.52 \\
\hline [Q5] Value & 0.76 & 0.57 & 0.63 & 0.52 & 1 \\
\hline
\end{tabular}

After these results were finalized with a final total of 720 responses recorded, there were only direct correlations between the components and no inverse correlations were identified. The two factors that had the highest correlation with one another was the value with the Customer Satisfaction levels and the Attentive/ Courteous component. The results were 0.76 and 0.63 respectively. The results concluded there is a low strength relationship between the variables Attentive/ Courteous and Overall Satisfaction with the effect on the customer service environment.

\section{Conclusions}

\section{Limitations}

However, this research contains constraints in pertinence to population, the amplitude of data accumulated, not accounted influence of other factors, and data reliability. To start, the population of this research was only limited to Chick-fil-A customers. Other fast food restaurants' attributes were not accounted for or analyzed. Other studies have conducted similar research with different restaurants, while this researcher only focused on one Chick-fil-A location 
in Teterboro, New Jersey. This limits analytics from other places and doesn't give an overall representation of other fast-food chains, but also additional Chick-fil-A locations across the United States, or New Jersey as a whole. In regards to the amount of data collected, only 720 respondents were used for this research. There were 3,893 responses in the system and the researcher only chose 720 . This only accounted for $18.5 \%$ of the total population of this Chickfil-A location, which disregarded those additional feedback reports. For each survey, they were only distributed to each 5th recipient, so there were unheard opinions and comments regarding their Chick-fil-A experience. That also goes along with customers not reporting their feedback because they may not have received the receipt, or they discarded it. Alongside, this research study only used data from January 1st, 2018 to December 31st, 2019, even though the store opened May 2017. This research only accounted for whole years' worth of data. In continuation, the data reliability may have had human error in the process when putting the data into QuestionPro's software. Although there isn't a definitive way of knowing this, incorrect numbers may have been put in for each of the 4 components and the overall value using the numerical data of the scale from 1-5.

\section{Discussion and Applications of Conclusion}

These results indicate that there was a low correlation between these two components (customer satisfaction and attentive/courteous) in relevance to the value of the customer environment from the customers' feedback.

Although the other variables fast service and cleanliness are important factors to take into consideration when seeing the overall effect, they have on the value of customer perception, they had correlations but not as significant as Attentive/Courteous and Overall Satisfaction with the service provided. For instance, the Fast Service and Cleanliness components had values 0.57 and 0.52 respectively, did not meet the 0.6 and over correlation, but demonstrated they had close relationships with the value of customer perception. Because this is the case, it is important to recognize that the 2 main components, Overall Satisfaction and Attentive/ Courteous with values of 0.76 and 0.63 respectively, are important for the franchise to continue to be leading at the top because of its well-known customer service. Being able to analyze one specific Chick-fil-A location, known to be in the top $20 \%$ of all Chick-fil-as in the United States is extremely important. Analyzing it from one of the top restaurants in the industry, it will be one of the ways other franchises will be able to use as guidance to strengthen their customer service components.

For this researcher and other researchers interested on the topic of analyzing fast food businesses, future directions will (hopefully) not only look into other Chick-fil-A stores, but also other fast food restaurant components to focus on. This will give restaurants a better understanding of what to focus on for improving customer service, so customers are able to have a more pleasurable experience with their dining in and carrying out experiences. This will not only increase the ranking for the overall restaurant but will have a positive impact on their sales and how the company is perceived. For instance, Marketing Science Institute (MSI) research determines the impacts of market value, challenging efficient hypotheses, comprehending what transpires in the market industry, and brand value evaluations. When there are new improvements for insights of customers, investment, and uprising technology, this would lead to an investment-oriented approach as to what to focus on for the business. so that way they are to have the a great customer service impact, and having people come back for more in the future, similar to the way that Chick-filA does because it is known as an overall franchise to have a positive impact on the people who encounter their service (Kumar 2015; Hornig, Tobias, et al 2013).

\section{Future Directions}

In terms of this Chick-fil-A, they will be able to see what they can improve on in the future and implement those changes. The way they will be able to implement the changes would be asking questions and interpreting the results further, possibly by separating it into the years 2018 and 2019, and determining what needs to be worked on the most, 
and why it was lacking. This will enable them to have higher rates of value overall in the customer service environment, and increase their profit margins throughout the business, as it continues to become more successful.

With this analysis, it will benefit both Chick-fil-A and other franchises because they will be able to see a different alternative in order to determine the most effective ways to measure their effects on the customer service environment. They will be able to make improvements for the future especially if they want the business to expand and grow because they have factors to prioritize. This will have people coming back for improved future experiences because of how the businesses overall impact their consumers.

\section{Acknowledgments}

I would like to thank Ms. Norina Sfeir for helping me with this project.

\section{References}

Al-Shammari, M., \& Kanina , A. S. (2015). Service Quality and its Relationship with ... Retrieved from https://globaljournals.org/GJMBR Volume14/2-Service-Quality-and-its-Relationship.pdf

Araujo, C., Araujo, C., \& Digital Enterprise. (2018, April 16). Why the customer experience is the future of monitoring. Retrieved from https:/www.cio.com/article/3268762/whythe-customer-experience-is-the-future-of-monitoring.html

Batt, R. (1999). Work Organization, Technology, and Performance in Customer Service and Sales. ILR Review, 52(4), 539-564. doi: 10.1177/001979399905200403

Cattin, P., \& Wittink, D. R. (1982). Commercial Use of Conjoint Analysis: A Survey. Journal of Marketing, 46(3), 44. doi: 10.2307/1251701

Lin, C.-C., \& Hsu, I.-C. (2008, January). A Conjoint Study of the Relationship between Website Attributes and Consumer Purchase Intentions. Retrieved from https://www.researchgate.net/publication/221229383 A Conjoint Study of the Relationship between Website Attributes and Consumer Purchase Intentions

Customer Experience Monitoring. (2019, May 20). Retrieved from https://cyara.com/solutions/customer-experience-monitoring/

Emotional Inquiry - brandtrust.com. (2019). Retrieved from http://brandtrust.com/site/wp-content/uploads/2014/11/emotional inquiry whitepaper.pdf

Han, H., \& Ryu, K. (2009). The Roles of the Physical Environment, Price Perception, and Customer Satisfaction in Determining Customer Loyalty in the Restaurant Industry. Journal of Hospitality \& Tourism Research, 33(4), 487-510. doi: 10.1177/1096348009344212

Haumann, T., Quaiser, B., Wieseke, J., \& Rese, M. (2014). Footprints in the Sands of Time: A Comparative Analysis of the Effectiveness of Customer Satisfaction and Customer-Company Identification over Time. Journal of Marketing, 78(6), 78-102. doi: 10.1509/jm.13.0509 
Hoffman, D. (2017, April 4). New Medias Impact on the Fast Food Industry: A ... Retrieved from https://opensiuc.lib.siu.edu/cgi/viewcontent.cgi? article $=2043 \&$ context $=$ gs rp

Hornig, Tobias, et al. "The Role of Culture for Pricing Luxury Fashion Brands." Marketing: Zeitschrift Für Forschung Und Praxis, vol. 35, no. 2, 2013, pp. 118-130., www.jstor.org/stable/41922281.

Kashif, M., Awang, Z., Walsh, J., \& Altaf, U. (2015). I'm loving it but hating US. British Food Journal, 117(9), 2344-2360. doi: 10.1108/bfj-01-2015-0040

Koo, L., Tao, F. K., \& Yeung, J. H. (1999). Preferential segmentation of restaurant attributes through conjoint analysis. International Journal of Contemporary Hospitality Management, 11(5), 242253. doi: 10.1108/09596119910272784

Kumar, V. "Evolution of Marketing as a Discipline: What Has Happened and What to Look Out For." Journal of Marketing, vol. 79, no. 1, 2015, pp. 1-9. JSTOR, www.jstor.org/stable/43784378.

Lin, I. Y., \& Mattila, A. S. (2010). Restaurant Servicescape, Service Encounter, and Perceived Congruency on Customers Emotions and Satisfaction. Journal of Hospitality Marketing \& Management, 19(8), 819-841. doi: 10.1080/19368623.2010.514547

Namin, A. (2017). Revisiting customers perception of service quality in fast food restaurants. Journal of Retailing and Consumer Services, 34, 70-81. doi: 10.1016/j.jretconser.2016.09.008

Qin, G., \& Prybutok, V. R. (2008). Determinants of Customer-Perceived Service Quality in Fast-Food Restaurants and Their Relationship to Customer Satisfaction and Behavioral Intentions. Quality Management Journal, 15(2), 35-50. doi: 10.1080/10686967.2008.11918065

Rhee, H. T., Yang, S.-B., Koo, C. \& Chung N. (2015). How Does Restaurant Attribute Importance Differ by the Type of Customer and Restaurant? Exploring TripAdvisor Reviews. Retrieved from http://agrilife.org/ertr/files/2015/02/SP03 ReviewSession Lee.pdf

Rhee, H. T., Yang, S.-B., \& Kim, K. (2016). Exploring the comparative salience of restaurant attributes: A conjoint analysis approach. International Journal of Information Management, 36(6), 13601370. doi: 10.1016/j.ijinfomgt.2016.03.001

Ryu, K., \& Han, H. (2009). Influence of the Quality of Food, Service, and Physical Environment on Customer Satisfaction and Behavioral Intention in Quick-Casual Restaurants: Moderating Role of Perceived Price. Journal of Hospitality \& Tourism Research, 34(3), 310-329. doi: 10.1177/1096348009350624

Schaupp, C. L., \& Belanger , F. (2005). A Conjoint Analysis of Online Consumer Satisfaction. Journal of Electronic Commerce Research , 6(2), 95-111. Retrieved from http://web.csulb.edu/journals/jecr/issues/20052/paper2.pdf

Sutton, R. I., \& Rafaeli, A. (1988). Untangling the Relationship between Displayed Emotions and Organizational Sales: The Case of Convenience Stores. Academy of Management Journal, 31(3), 461487. doi: $10.5465 / 256456$ 
Swan, J. E., Trawick, I. F., \& Carroll, M. G. (1981). Effect of Participation in Marketing Research on Consumer Attitudes toward Research and Satisfaction with a Service. Journal of Marketing Research, 18(3), 356. doi: 10.2307/3150976

Tarka, P. (2008, September). Conjoint analysis within the field of customer satisfaction problems -a model o composite product/ service. Retrieved from https://www.researchgate.net/publication/237081062 Conjoint analysis within the field of customer satisfaction problems a model o composite productservice

Vogel, V., Evanschitzky, H., \& Ramaseshan, B. (2008). Customer Equity Drivers and Future Sales. Journal of Marketing, 72(6), 98-108. doi: 10.1509/jmkg.72.6.098

Yim, C. K. (B., Tse, D. K., \& Chan, K. W. (2008). Strengthening Customer Loyalty through Intimacy and Passion: Roles of Customer-Firm Affection and Customer-Staff Relationships in Services. Journal of Marketing Research, 45(6), 741-756. doi: 10.1509/jmkr.45.6.741 